\title{
CLINICAL EVALUATION OF BRINALDIX A NEW ORAL DIURETIC
}

\author{
J. D. BriggS, M.B. Glasg., M.R.C.P., M.R.C.P.E., \\ Registrar.
}

\author{
R. N. M. McSweEn, M.B., B.Sc. Glasg., \\ M.R.C.P.E., M.R.C.P., Glasg., \\ Senior House Officer*.
}

A. C. KenNedy, M.D. Glasg., F.R.C.P.E., F.R.C.P. Glasg.,

Senior Lecturer.

University Department of Medicine, Royal Infirmary, Glasgow.

SINCE Novello and Sprague (1957) first introduced chlorothiazide as an effective oral diuretic, it and its many derivatives have come to assume a position of great importance in diuretic therapy. Despite their proven worth, however, the search for an ideal diuretic-one having an effective action, freedom from toxic effects and absence of undesirable electrolyte disturbances-has gone ahead. In particular, the search has continued for agents less prone to induce potassium depletion.

We report here the results of volumetric and biochemical studies on a new substance 'Brinaldix' which, from preliminary clinical reports (von Arx, 1963; Calandra, Aguzzi, Rottini, Pugliese and Latini, 1963; Pupita, Molaschi, Bartoli and Doglio, 1963; Schmuziger, 1963; Stirati and Cinotti, 1963; Thürlimann, 1963) has been found to be an effective diuretic. In addition, animal experiments (Flückiger, Schalch and Taeschler, 1963; Jucker, Lindenmann, Schenker, Flückiger and Taeschler, 1963) indicated that this substance produced little potassium diuresis.

'Brinaldix' is one of a number of synthetic 3-sulfamoyl-4-halogen benzene derivatives (Jucker and others, 1963), its chemical name being 4-chloro-N-(2, 6-dimethyl piperidino)-3 sulfamoyl benzamide. Its chemical formula with that of bendrofluazide for comparison is shown in Fig. 1. The chlorothiazide compounds also contain a sulfamoyl group, but the structural formula of 'Brinaldix' shows marked differences from these substances. It also contains a

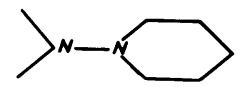

'bridge' grouping similar to that of some hydrazine compounds, but in vitro animal studies (Ellis, 1963) have failed to show that it has any inhibitory effects on monoamine oxidase.

* Present address:

Department of Pathology, Western Infirmary, Glasgow.
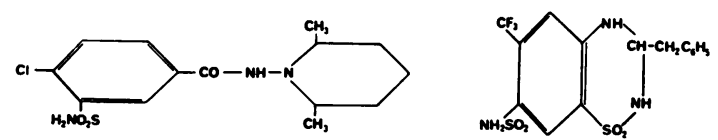

FIG. 1.-Chemical structure of (a) 'Brinaldix' and (b) bendrofluazide.

\section{Materials and Methods}

Two healthy young males (subjects 1,2 ) were each given $20,40,60$ and $80 \mathrm{mg}$. doses of 'Brinaldix', and one $7.5 \mathrm{mg}$. dose of bendrofluazide on separate days with intervals of at least 5 days between each dose. A further healthy male control (subject 3 ) received only the 20 and $40 \mathrm{mg}$. doses of 'Brinaldix' (vide infro). Urine collections were made for the 24-hour period before the drug was given, and for three consecutive 8-hour periods thereafter. On the days of the experiments the subjects were on an unrestricted diet, continued moderate activity and had a fixed fluid intake of 2 litres. The urine collections were analysed in respect of volume, sodium, chloride and potassium. Dose-response curves were plotted for each subject.

A clinical trial was conducted on fourteen in patients with oedema, one patient being included in the trial on each of two separate hospital admissions. Oedema was due to congestive cardiac failure in six patients, hepatic cirrhosis in four patients and a nephrotic syndrome in the remaining four patients (Table 1). With the exception of Cases 1 and 2A, all patients received two morning doses of $60 \mathrm{mg}$. 'Brinaldix', and two morning doses of $7.5 \mathrm{mg}$. bendrofluazide, the two drugs being used consecutively and at 2-day intervals, on an ABBA and BAAB pattern, the two patterns alternating in different patients. The urine was collected for the 24-hour period prior to giving the drug, and in respect of 'Brinaldix' for three consecutive 8-hour periods and one 24-hour period thereafter, and in respect of bendrofluazide for two consecutive 24-hour periods thereafter. For the period of the trial the patients were on a sodium restricted diet providing approximately $17 \mathrm{mEq}$. sodium $/ 24$ hours. No alteration in physical activity between the control and test periods was permitted. In cases 9,12 and 14 potassium supplements as potassium chloride, $1 \mathrm{~g}$. three times a day, were given because of hypokalemia at the commencement of the trial (see Table 1). Volumetric and biochemical studies were carried out as in the 


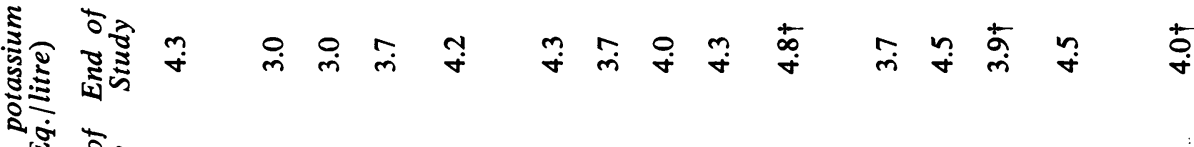

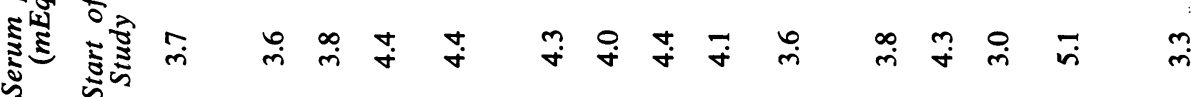

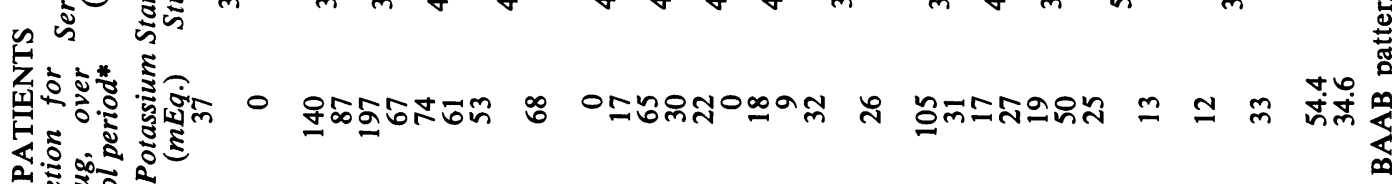

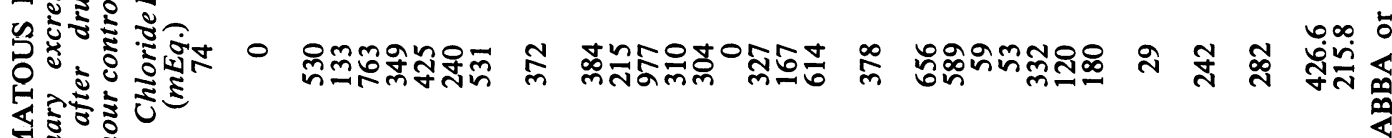

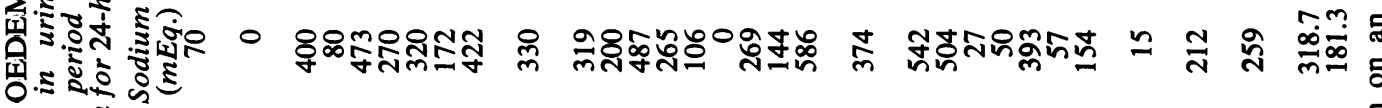

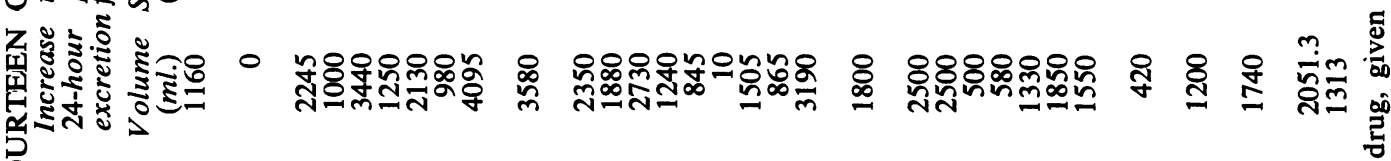
官

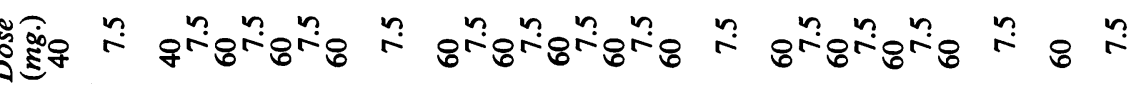
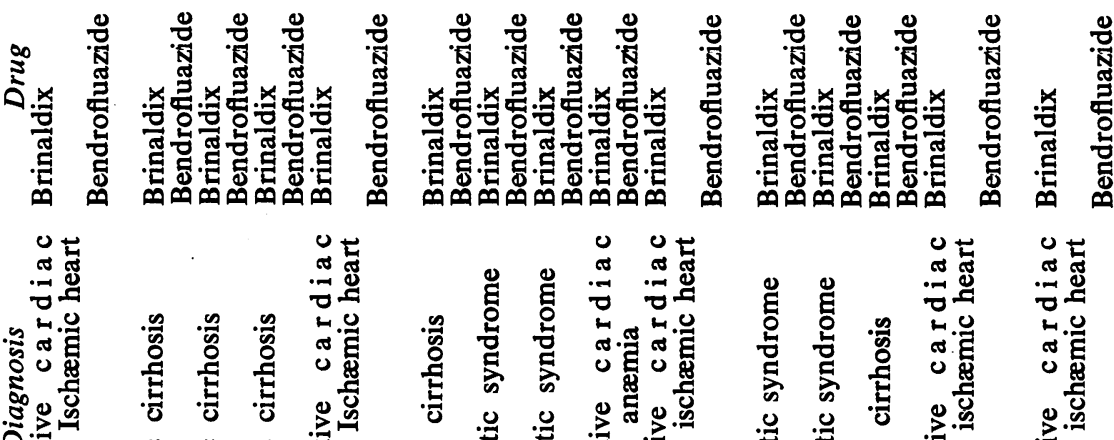

80

总芯塄
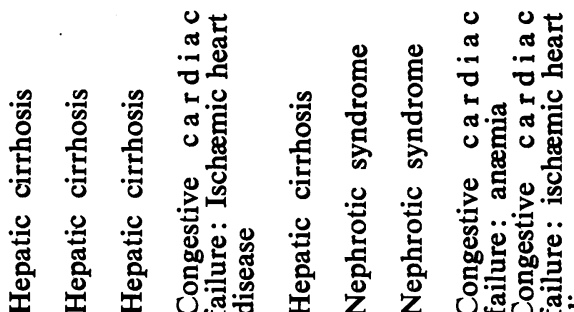

\%

兽

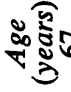

요

ช.

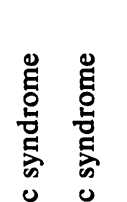

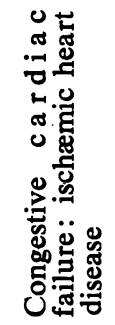

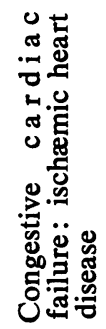

ฮี

능 8

我旅

흥잉

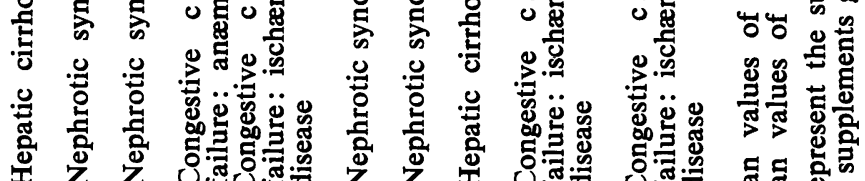

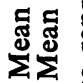

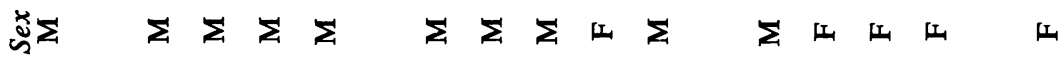

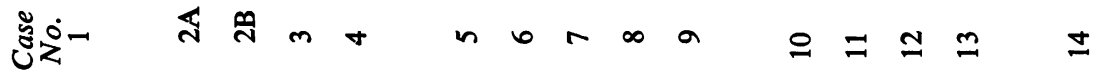


TABLE 2

DETAILED VOLUMETRIC AND BIOCHEMICAL FINDINGS IN TWO NORMAL SUBJECTS AFTER 20, 40, 60 AND $80 \mathrm{MG}$. DOSES OF 'BRINALDIX' AND AFTER A 7.5 MG. DOSE OF BENDROFLUAZIDE.

Increase in urinary excretion tor $24 \mathrm{hr}$. period after drug, over ex cretion for $24 \mathrm{hr}$. control period.

Drugs $\quad \begin{gathered}\text { Dose } \\ \text { (mg.) Subject (ml.) }\end{gathered}$

$\begin{array}{lllllll} & & 1 & 1470 & 191.4 & 286 & 34 \\ \text { 'Brinaldix' } & 20 & 2 & 2260 & 226.5 & 306 & 24 \\ & & 1 & 2010 & 293.5 & 383.3 & 35.5 \\ \text { 'Brinaldix' } & 40 & 2 & 2610 & 389 & 472 & 24 \\ & & 1 & 3225 & 381 & 457 & 53.5 \\ \text { 'Brinaldix' } & 60 & 2 & 3295 & 487 & 546 & 18.5 \\ \text { 'Brinaldix' } & 80 & 2 & 2940 & 285 & 280 & 51 \\ & & 1 & 398 & 446 & 34.5 \\ \text { Bendrofluazide } & 7.5 & 2 & 2428 & 273.5 & 349 & 38.5\end{array}$

normal subjects. Serum electrolytes were estimated at the commencement of the trial and on the day immediately after giving the last drug dose.

\section{Results}

The detailed volumetric and biochemical findings for normal subjects 1 and 2 are given in Table 2 . Owing to the side-effects which developed in subject 3 , he was withdrawn from the trial having had only the 20 and $40 \mathrm{mg}$. doses of 'Brinaldix'. The results show an increasing urinary volume output with doses of 20,40 and $60 \mathrm{mg}$. of 'Brinaldix', whereas a dose of $80 \mathrm{mg}$. gave a response intermediate between that for the 40 and $60 \mathrm{mg}$. doses. In the light of these findings it was decided to use a $60 \mathrm{mg}$. dose for the clinical trial. An intense sodium and chloride diuresis accompanied the water diuresis. A potassium diuresis also occurred, but this was not so marked as that for sodium. In subject 1 the potassium diuresis was slightly less than, and in subject 2 markedly less than that produced by a $7.5 \mathrm{mg}$. dose of bendrofluazide.

As shown in Fig. 2 the urine flow after a $60 \mathrm{mg}$. dose of 'Brinaldix' was maximal in the first 8-hour period after administering the drug, but a good diuresis was still present in the 16-24 hour period. 2. Oedematous subjects.

The detailed volumetric and biochemical findings are given in Table 2 . Cases 1 and $2 A$ received a $40 \mathrm{mg}$. dose of 'Brinaldix' whereas the remainder received $60 \mathrm{mg}$.

In ten out of the fourteen cases the increase in urine volume for the dose of 'Brinaldix' exceeded that for a $7.5 \mathrm{mg}$. dose of bendrofluazide. In case 10 the increases in volume were equal, whereas in cases 11,12 and 14 bendrofluazide produced the better response. In cases 1 and 7 where bendrofluazide was ineffective 'Brinaldix' increased the urine volume by 1160 and $845 \mathrm{ml}$. respectively. The overall average in urine volume for 'Brinaldix' was well in excess of that for bendrofluazide.

When the results were grouped according to the type of oedema from which the patient was suffering the percentage increase in volume for each group was greater in respect of 'Brinaldix' than that for bendrofluazide.

The pattern of diuretic response (Fig. 2) varied in the three groups, the maximum urine flow in the cardiac cases occurring in the 16-24 hour period, in the hepatic cases in the 8-16 hour period, and in the renal cases in the 1-8 hour period. In all 3 groups there was still a substantial increase in urine flow in the 24-48 hour period after administering the drug.

The electrolyte studies in the ten cases who showed
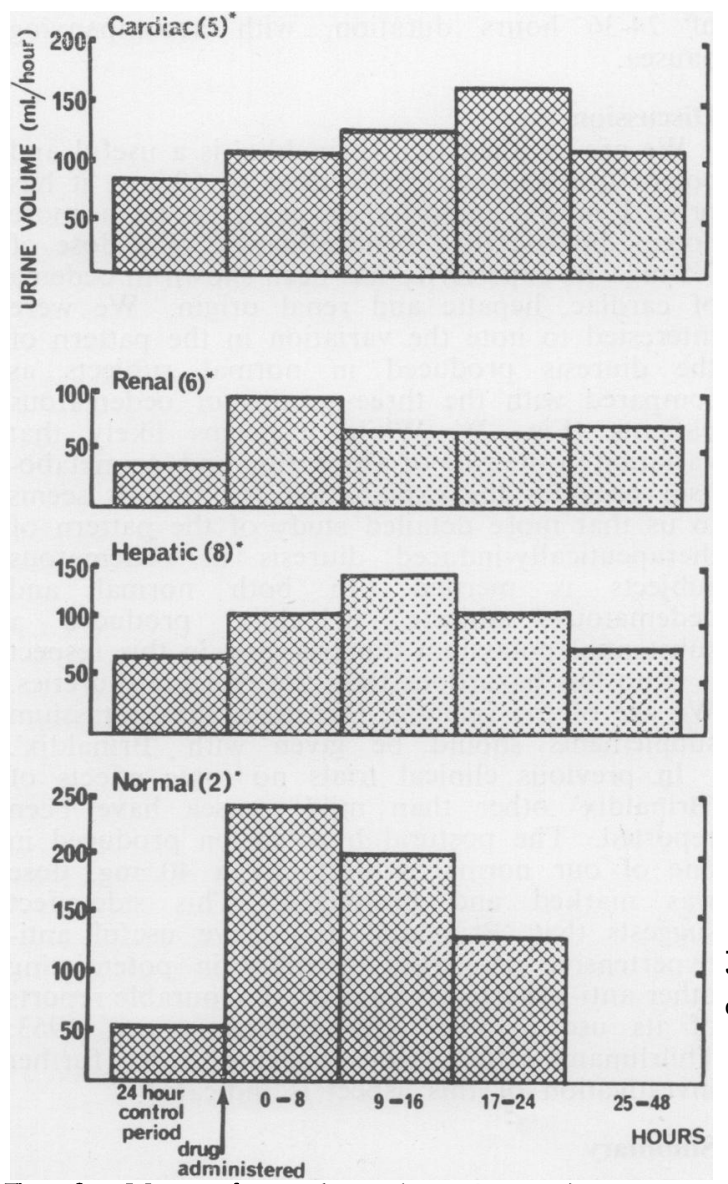

FIG. 2.-Mean of stated number of experiments.

PATTERN OF URINARY EXCRETION FOLLOWING A 60 MG. DOSE OF 'BRINALDIX' IN TWO NORMAL SUBJECTS AND IN PATIENTS WITH OEDEMA OF VARIOUS CAUSES.

a superior water diuresis with 'Brinaldix' also showed a superior sodium and chloride diuresis with this compound. In case 12 , although there was a superior water diuresis with bendrofluazide, the sodium and chloride excretion was substantially better with 'Brinaldix'. In cases 10,11 and 14 the sodium and chloride diuresis were either equal in respect of the two compounds or slightly superior with 'Brinaldix'. A potassium diuresis was produced with 'Brinaldix' in all except case 5 . The mean potassium loss was greater with 'Brinaldix' than with bendrofluazide.

In four out of the eleven patients who were not on potassium supplements a small fall in the serum potassium occurred over the trial period, i.e. after two $60 \mathrm{mg}$. doses of 'Brinaldix' and two $7.5 \mathrm{mg}$. doses of bendrofluazide.

\section{Side Effects}

In none of the fourteen patients studied were there any subjective or objective toxic effects. In normal subjects 1 and 2 some nausea and headache were complained of on the morning after taking the drug. In normal subject 3 a dose of $40 \mathrm{mg}$. produced postural hypotension 
of 24-36 hours duration, with accompanying nausea.

\section{Discussion}

We are satisfied that 'Brinaldix' is a useful and potent oral diuretic. In a dose of $60 \mathrm{mg}$. it has proved in the majority of cases to be a more potent diuretic than bendrofluazide in a dose of $7.5 \mathrm{mg}$. Its superiority has been shown in oedema of cardiac, hepatic and renal origin. We were interested to note the variation in the pattern of the diuresis produced in normal subjects as compared with the three groups of oedematous patients (Fig. 2). While it seems likely that variation in the rate of absorption and/or metabolism provides the explanation for this, it seems to us that more detailed study of the pattern of therapeutically-induced diuresis in oedematous subjects is merited. In both normal and oedematous subjects 'Brinaldix' produced a substantial potassium diuresis, and in this respect it is no less hazardous than the thiazide diuretics. We are of the opinion, therefore, that potassium supplements should be given with 'Brinaldix'.

In previous clinical trials no toxic effects of 'Brinaldix' other than mild nausea have been reported. The postural hypotension produced in one of our normal subjects by a $40 \mathrm{mg}$. dose was marked and prolonged. This side-effect suggests that 'Brinaldix' may have useful antihypertensive properties, possibly in potentiating other anti-hypertensive agents. Favourable reports of its use in hypertension (Schmuziger, 1963; Thürlimann, 1963) have appeared and further investigation of this aspect is indicated.

\section{Summary}

'Brinaldix', a new non-thiazide oral diuretic, has been used in a trial on three normal subjects and fourteen patients with oedema from various causes. It is a potent salidiuretic and proved superior to bendrofluazide in 10 out of $14 \cong$ patients. It produced a substantial potassium 3 diuresis, and we are of the opinion that potassium $\stackrel{\varnothing}{\varrho}$ supplements should be given in conjunction with $C$. it. In one normal subject it produced a period $\vec{F}$ of postural hypotension; no other major side- $\stackrel{?}{\stackrel{\rho}{\rho}}$ effects were noted.

We wish to thank Miss Mary B. J. Gray for $\frac{\bar{\sigma}}{\bar{C}}$ valuable technical assistance, and Sandoz Products Limited for supplies of 'Brinalidx'.

\section{REFERENCES}

Von Arx, A. (1963): Clinical Experience with the $\vec{\circ}$ New Salidiuretic Brinaldix in the Treatment of Oedema, Ther. Umsch., $20,423$.

Calandra, P., Aguzzi, P., Rottini, E., Pugliese, F., and LATINI, P. (1963): Effect of a New Synthetico Drug on Water and Salt Elimination and on the 3 Blood Concentration of Certain Electrolytes, Clin. ter., 27, 668 .

Ellis, R. A. (1963): Personal Communication.

Fluckiger, E., SCHALCH, W., TAESCHLER, M. (1963): $\underset{\nexists}{\mp}$ Brinaldix (DT-327), a New Salidiuretic, Schweiz. $\vec{\theta}$ med. Wschr., 93, 1232.

JUCKER, E., LINDENMANN, A., SCHENKER, E., Fluckiger, E., and TAESCHLER, M. (1963): Constitution and Salidiuretic Action of 3-sulfamyl-4- chlorbenzoic Acid and Associated Compounds, $D$ Arzneimittel-Forsch., 13, 269.

Novello, F. C., SPRAGue, J. M. (1957): Benzothiadiazine Dioxides as Novel Diuretics, J. Am\&. chem. Soc., 79, 2028.

Pupita, F., Molaschi, M., Bartoli, E., and Dogl R. (1963): Diuretic Effect of Clopamide (Brinaldi Gazz. intern. Med. Chir., 68, 2317.

SCHMUZIGER, P. (1963): Brinaldix, a New Salidiuretic, Praxis, 52, 1066.

Stirati, G., CinotTi, G. A. (1963): Preliminary Clinical and Biological Results with DT 327, a 2 New Oral Diuretic, Gazz. intern. Med. Chir., 67/68, $\overline{\overline{9}}$ 2532.

ThurlimanN, E. (1963): The New Salidiuretic Brinaldix in the Outpatient Treatment of Internal Disorders, Ther. Umsch., 20, 426. 